\title{
Enthalpies of solvation of hydroxyl cyclohexane derivatives in different solvents
}

\author{
Felisbela S. Costa, \\ Laboratório de Métodos Instrumentais de Análise, Faculdade de Farmácia, \\ Universidade de Coimbra, Coimbra, Portugal \\ M. Ermelinda Eusébio, J. S. Redinha, and M. Luísa P. Leitão ${ }^{a}$ \\ Departamento de Química, Universidade de Coimbra, Coimbra, Portugal
}

\begin{abstract}
The enthalpies of solution of cyclohexanol, cis-1,2-cyclohexanediol, and myo-inositol in water, formamide, and dimethylsulphoxide at $T=298.15 \mathrm{~K}$ as well as their enthalpies of vaporization or sublimation were determined. The enthalpies of solvation were calculated from the data obtained. The contributions of the polar and non-polar groups to the behaviour of the solute molecules in polar solvents are analysed by using the enthalpy of solvation data. (C) 1999 Academic Press
\end{abstract}

KEYWORDS: solution enthalpy; sublimation enthalpy; non-electrolyte solutions; hydroxyl cyclohexane derivatives

\section{Introduction}

A large number of non-electrolytes are made up of molecules containing polar and nonpolar groups. The behaviour of these compounds in solvents depends, in a complex way, on the solute and solvent nature as well as on the preponderant polar or non-polar part.

Besides contributing to a general understanding of molecular interactions of non-electrolytes with solvents, studies of this type are important in biochemistry as many compounds of biological interest belong to this class of solutes. Data on the solvation of similar solutes, differing only in the ratio of polar to non-polar groups in various solvents, provide an insight into solute-solvent interactions.

The enthalpy of solvation $\Delta_{\text {solv }} H_{\mathrm{m}}$ of cyclohexanol, cis-1,2-cyclohexanediol, and myoinositol in polar solvents are presented here. Water (W), formamide (FMD), and dimethylsulphoxide (DMSO) were used as solvents. All solute molecules have cyclohexyl rings which differ from each other only by the number of hydroxyls attached to them. The solvents were selected with the aim of evaluating the effect of their molecular features on solvation, and in particular, for comparing the behaviour of solvent water with that of other polar liquids.

${ }^{a}$ To whom correspondence should be addressed (E-mail: mlleitao@ cygnus.ci.uc.pt). 
TABLE 1. Densities $\rho$ at $T=298.15 \mathrm{~K}$, and melting temperatures $T_{\text {fus }}$ of the compounds investigated in this work, and comparison with literature values

\begin{tabular}{|c|c|c|c|c|}
\hline \multirow[t]{2}{*}{ Compound } & \multicolumn{2}{|c|}{$\rho /\left(\mathrm{kg} \cdot \mathrm{m}^{-3}\right)$} & \multicolumn{2}{|c|}{$T_{\text {fus }} / \mathrm{K}$} \\
\hline & this work & literature & this work & literature \\
\hline \multirow[t]{3}{*}{ Formamide } & $1129.2 \pm 0.2$ & $1129.15^{a}$ & $275.7 \pm 0.4$ & 275.5 to $275.7^{c}$ \\
\hline & & $1129.23^{b}$ & & $275.8^{g}$ \\
\hline & & $1129.18^{c}$ & & $275.6^{h}$ \\
\hline \multirow[t]{4}{*}{ Dimethylsulphoxide } & $1095.29 \pm 0.04$ & $1095.37^{b}$ & $291.6 \pm 0.2$ & $291.75^{i}$ \\
\hline & & $1095.3^{d}$ & & 291.2 to $291.7^{g}$ \\
\hline & & $1095.307^{e}$ & & $291.67^{j}$ \\
\hline & & $1095.6^{f}$ & & \\
\hline \multirow[t]{3}{*}{ Cyclohexanol } & & & $298.0 \pm 0.3$ & $297.0^{k}$ \\
\hline & & & & $299.05^{l}$ \\
\hline & & & & $297.92^{m}$ \\
\hline cis-1,2-Cyclohexanediol & & & $371.5 .3 \pm 0.2$ & $371.6 \pm 0.2^{n}$ \\
\hline \multirow[t]{2}{*}{ myo-Inositol } & & & $497.1 \pm 0.3$ & 496 to $498^{g}$ \\
\hline & & & & $496.9^{\circ}$ \\
\hline
\end{tabular}

\footnotetext{
${ }^{a}$ Reference 1. ${ }^{b}$ Reference 2. ${ }^{c}$ Reference 3. ${ }^{d}$ Reference $4 .{ }^{e}$ Reference 5. ${ }^{f}$ Reference 6. ${ }^{g}$ Reference 7. ${ }^{h}$ References 1 and $8 .{ }^{i}$ References 9 and 10. ${ }^{j}$ Reference $11 .{ }^{k}$ Reference 12. ${ }^{l}$ Reference 13. ${ }^{m}$ Reference $14 .{ }^{n}$ Reference $15 .{ }^{o}$ Reference 16.
}

\section{Experimental}

The water used in the preparation of the solutions was obtained from a Millipore purifier (ASTM type I). Formamide (Merck, pro analysis, mass fraction $>0.995$ ) was purified by vacuum distillation. Dimethylsulphoxide (Merck, pro analysis, mass fraction $>0.995$, water mass fraction $<3 \cdot 10^{-4}$ ), cyclohexanol (Merck, for synthesis, mass fraction $>0.99$, water mass fraction $<2 \cdot 10^{-3}$ ), cis-1,2-ciclohexanediol (Aldrich, mass fraction 0.99), and myoinositol (Merck, for biochemistry, mass fraction $>0.99$ ) were used without further purification. The water mass fractions in formamide and in dimethylsulphoxide were determined using the Karl Fisher method and were found to be $(1.9 \pm 0.3) \cdot 10^{-3}$ and $(4.6 \pm 0.3) \cdot 10^{-4}$, respectively. The densities of the compounds that are liquid at $T=298.15 \mathrm{~K}$ were determined using a vibrating-tube densimeter and the resulting values are presented in table 1. In this table, the melting temperatures of the compounds, which were determined by d.s.c., are also included. As can be seen from table 1, the present values are in close agreement with the literature ones.

Solution calorimetric determinations were performed with a C-80 SETARAM mixing calorimeter. A standard reversal mixing cell supplied by the manufacturer was used. In order to avoid contamination by air moisture, the cell assembly was always carried out in a dry nitrogen box. The upper limit of the molality of the solutions obtained was $(0.4$ to 0.5$) \mathrm{mol} \cdot \mathrm{kg}^{-1}$ unless the solubility limited the experiments to a lower concentration range. The experiments were performed at $T=298.15 \mathrm{~K}$ except for those involving 
cyclohexanol, which were carried out at $T=300.15 \mathrm{~K}$. The calorimeter calibration was carried out electrically, and the calorimetric procedure was tested chemically by measuring the enthalpy of solution of potassium chloride in water. For this system, we obtained $\Delta_{\text {sol }} H_{\mathrm{m}}\left(0.1110 \mathrm{~mol} \cdot \mathrm{kg}^{-1}\right)=(17.63 \pm 0.06) \mathrm{kJ} \cdot \mathrm{mol}^{-1}$ as an average of seven determinations. This result compares well with the literature value $\Delta_{\text {sol }} H_{\mathrm{m}}\left(0.1110 \mathrm{~mol} \cdot \mathrm{kg}^{-1}\right)=$ $(17.584 \pm 0.017) \mathrm{kJ} \cdot \mathrm{mol}^{-1}$. (17)

The equipment used for determining the sublimation and vaporization enthalpies consisted of a calorimetric block to which a vacuum system capable of attaining a vacuum of about $p=1 \cdot 10^{-4} \mathrm{~Pa}$ was connected. The values quoted for the enthalpy of sublimation, or vaporization of each substance are the mean of the results of seven runs. The details of the experimental procedure used here were described elsewhere. ${ }^{(15)}$

The enthalpy of solvation was determined from the values obtained for the enthalpy of solution and the enthalpy of sublimation, or vaporization according to the equation:

$$
\Delta_{\text {solv }} H_{\mathrm{m}}=\Delta_{\text {sol }} H_{\mathrm{m}}-\Delta_{\text {sub }} H_{\mathrm{m}} .
$$

For liquid solutes $\Delta_{\text {sub }} H_{\mathrm{m}}$ becomes $\Delta_{\mathrm{vap}} H_{\mathrm{m}}$. As $\Delta_{\mathrm{sub}} H_{\mathrm{m}}$ and $\Delta_{\mathrm{vap}} H_{\mathrm{m}}$ were determined at a temperature different from $T=298.15 \mathrm{~K}$, heat capacity data for the gas $C_{p, \mathrm{~m}}^{\mathrm{g}}$ and solid, or liquid phases $C_{p, \mathrm{~m}}^{*}$ were needed to convert the experimental results to the reference temperature. Except for cyclohexanol, no heat capacity data are available for the compounds considered in this work. However, for this substance, no correction was needed since the temperature at which the experiments were performed was close to the reference.

The heat capacity of solid myo-inositol and cis-1,2-cyclohexanediol were determined by using a Perkin Elmer DSC7 instrument. Aluminium pans of $40 \mu \mathrm{l}$ were employed and temperature increments of $3 \mathrm{~K}$ were imposed at a scanning rate of $2 \mathrm{~K} \cdot \mathrm{min}^{-1}$. The mass of the sample and reference material ( $\alpha$-aluminium oxide) used in each experiment was about $20 \mathrm{mg}$. The reported results are the mean of seven determinations carried out on the sample and reference material alternately. The heat capacity in the gas phase was calculated by using group-contribution methods. ${ }^{(18,19)}$

\section{Results}

The results of the enthalpies of solution are presented in table 2, and those of the heat capacities of the diol and inositol in the solid and gas phases are presented in table 3 .

The standard enthalpy of sublimation $\Delta_{\text {sub }} H_{\mathrm{m}}^{\mathrm{o}}$ at $T_{\mathrm{o}}=298.15 \mathrm{~K}$ was calculated by using the expression:

$$
\Delta_{\mathrm{sub}} H_{\mathrm{m}}^{\mathrm{o}}=\Delta_{\mathrm{sub}} H_{\mathrm{m}}(T)+\int_{T}^{T_{\mathrm{o}}}\left(C_{p, \mathrm{~m}}^{\mathrm{g}}-C_{p, \mathrm{~m}}^{*}\right) \mathrm{d} T,
$$

where $T$ is the temperature of the experiment. As can be seen from the results given in table 3, the difference between the heat capacities of the gas and solid phases is, for both compounds, a linear function of temperature, and can therefore be expressed as:

$$
C_{p, \mathrm{~m}}^{\mathrm{g}}-C_{p, \mathrm{~m}}^{*}=a+b \cdot T,
$$

where $a$ and $b$ are parameters whose values were determined by linear regression and are presented in table 4 . 
TABLE 2. Enthalpy of solution $\Delta_{\mathrm{sol}} H_{\mathrm{m}}$ of hydroxyl cyclohexane derivatives in different solvents at $T=298.15 \mathrm{~K}$ and at various molalities $m$

\begin{tabular}{|c|c|c|c|c|c|}
\hline \multicolumn{2}{|c|}{ Cyclohexanol (W) } & \multicolumn{2}{|c|}{ Cyclohexanol (DMSO) } & \multicolumn{2}{|c|}{ Cyclohexanol (FMD) } \\
\hline$m$ & $\Delta_{\mathrm{sol}} H_{\mathrm{m}}$ & $m$ & $\Delta_{\mathrm{sol}} H_{\mathrm{m}}$ & $m$ & $\Delta_{\mathrm{sol}} H_{\mathrm{m}}$ \\
\hline$\overline{\mathrm{mol} \cdot \mathrm{kg}^{-1}}$ & $\overline{\mathrm{kJ} \cdot \mathrm{mol}^{-1}}$ & $\overline{\mathrm{mol} \cdot \mathrm{kg}^{-1}}$ & $\overline{\mathrm{kJ} \cdot \mathrm{mol}^{-1}}$ & $\overline{\mathrm{mol} \cdot \mathrm{kg}^{-1}}$ & $\overline{\mathrm{kJ} \cdot \mathrm{mol}^{-1}}$ \\
\hline 0.0641 & -8.543 & 0.1031 & 6.026 & 0.1393 & 4.744 \\
\hline 0.0708 & -8.540 & 0.1068 & 6.030 & 0.1440 & 4.740 \\
\hline 0.1002 & -8.465 & 0.1177 & 6.025 & 0.1948 & 4.726 \\
\hline 0.1189 & -8.425 & 0.1412 & 6.005 & 0.2331 & 4.719 \\
\hline 0.1361 & -8.420 & 0.1550 & 6.025 & 0.2419 & 4.707 \\
\hline 0.1402 & -8.376 & 0.1588 & 6.022 & 0.2672 & 4.732 \\
\hline 0.2268 & -8.129 & 0.2051 & 6.001 & 0.2819 & 4.703 \\
\hline 0.2400 & -8.113 & 0.2289 & 5.991 & 0.3197 & 4.698 \\
\hline 0.2603 & -8.100 & 0.2473 & 5.989 & 0.3304 & 4.686 \\
\hline 0.2818 & -8.051 & 0.2686 & 5.980 & 0.3727 & 4.678 \\
\hline 0.3192 & -7.918 & 0.3180 & 5.960 & 0.4430 & 4.680 \\
\hline 0.3470 & -7.914 & 0.3318 & 5.952 & 0.4800 & 4.655 \\
\hline 0.3989 & -7.722 & 0.3557 & 5.950 & & \\
\hline 0.4601 & -7.598 & & & & \\
\hline \multicolumn{2}{|c|}{ cis-1,2-cyclohexanediol (W) } & \multicolumn{2}{|c|}{ cis-1,2-cyclohexanediol (DMSO) } & \multicolumn{2}{|c|}{ cis-1,2-cyclohexanediol (FMD) } \\
\hline 0.0443 & 6.470 & 0.0459 & 19.193 & 0.0478 & 18.522 \\
\hline 0.0487 & 6.510 & 0.0560 & 19.123 & 0.0638 & 18.527 \\
\hline 0.1079 & 6.593 & 0.0770 & 19.053 & 0.1001 & 18.567 \\
\hline 0.1322 & 6.628 & 0.1000 & 19.057 & 0.1255 & 18.508 \\
\hline 0.1926 & 6.719 & 0.1044 & 19.035 & 0.1486 & 18.543 \\
\hline 0.2344 & 6.795 & 0.1120 & 19.252 & 0.1717 & 18.543 \\
\hline 0.2848 & 6.903 & 0.1602 & 19.189 & 0.1924 & 18.595 \\
\hline 0.3441 & 6.989 & 0.2220 & 19.138 & 0.2119 & 18.574 \\
\hline 0.3720 & 7.061 & 0.2241 & 19.258 & 0.2284 & 18.604 \\
\hline 0.4143 & 7.104 & 0.2575 & 19.194 & 0.2795 & 18.634 \\
\hline 0.4530 & 7.165 & 0.3189 & 19.222 & 0.3152 & 18.586 \\
\hline \multirow[t]{2}{*}{0.4802} & 7.225 & 0.3567 & 19.235 & 0.3428 & 18.666 \\
\hline & & & & 0.4184 & 18.613 \\
\hline 0.0167 & 15.544 & 0.0430 & 11.697 & 0.0403 & 14.765 \\
\hline 0.0242 & 15.535 & 0.0540 & 11.713 & 0.0532 & 14.774 \\
\hline 0.0272 & 15.538 & 0.0586 & 11.690 & 0.0650 & 14.784 \\
\hline 0.0600 & 15.500 & 0.0693 & 11.708 & 0.0752 & 14.782 \\
\hline 0.0717 & 15.504 & 0.0758 & 11.685 & 0.0841 & 14.780 \\
\hline 0.1011 & 15.465 & 0.0852 & 11.691 & 0.0983 & 14.794 \\
\hline 0.1680 & 15.408 & 0.0908 & 11.715 & 0.1126 & 14.790 \\
\hline 0.2052 & 15.310 & 0.1070 & 11.702 & 0.1250 & 14.802 \\
\hline 0.2470 & 15.335 & 0.1115 & 11.715 & 0.1346 & 14.807 \\
\hline 0.2691 & 15.247 & 0.1254 & 11.698 & & \\
\hline 0.3134 & 15.264 & & & & \\
\hline 0.3429 & 15.175 & & & & \\
\hline 0.4121 & 15.108 & & & & \\
\hline 0.4343 & 15.086 & & & & \\
\hline
\end{tabular}


TABLE 3. Solid phase heat capacity $C_{p, \mathrm{~m}}^{*}{ }^{a}$ and calculated gas phase heat capacities $C_{p, \mathrm{~m}}^{\mathrm{g}}{ }^{a}$ of $c i s-1,2$-cyclohexanediol and myo-inositol at different temperatures $T$

\begin{tabular}{|c|c|c|c|}
\hline$\frac{T}{\mathrm{~K}}$ & $\frac{C_{p, \mathrm{~m}}^{*}}{\mathrm{~J} \cdot \mathrm{K}^{-1} \cdot \mathrm{mol}^{-1}}$ & $\frac{C_{p, \mathrm{~m}}^{\mathrm{g}}}{\mathrm{J} \cdot \mathrm{K}^{-1} \cdot \mathrm{mol}^{-1}}$ & $\frac{C_{p, \mathrm{~m}}^{\mathrm{g}}-C_{p, \mathrm{~m}}^{*}}{\mathrm{~J} \cdot \mathrm{K}^{-1} \cdot \mathrm{mol}^{-1}}$ \\
\hline \multicolumn{4}{|c|}{ cis-1,2-Cyclohexanediol } \\
\hline 293.15 & $157.6 \pm 0.4$ & 145 & -13 \\
\hline 300.15 & $163.9 \pm 0.3$ & 148 & -15 \\
\hline 308.15 & $166.4 \pm 0.4$ & 150 & -16 \\
\hline 316.15 & $171.9 \pm 0.8$ & 153 & -19 \\
\hline 323.15 & $175.0 \pm 0.5$ & 156 & -19 \\
\hline 333.15 & $180.7 \pm 0.6$ & 159 & -22 \\
\hline 339.15 & $184.3 \pm 0.7$ & 161 & -23 \\
\hline 344.15 & $186.2 \pm 0.6$ & 163 & -24 \\
\hline \multicolumn{4}{|c|}{ myo-Inositol } \\
\hline 283.15 & $203.1 \pm 0.4$ & 215 & 12 \\
\hline 298.15 & $220.9 \pm 0.5$ & 218 & -3 \\
\hline 308.15 & $232.2 \pm 0.6$ & 222 & -11 \\
\hline 323.15 & $249.8 \pm 0.3$ & 224 & -26 \\
\hline 344.15 & $271.6 \pm 0.3$ & 229 & -43 \\
\hline 373.15 & $297.2 \pm 0.7$ & 233 & -64 \\
\hline 396.15 & $324.7 \pm 0.6$ & 236 & -89 \\
\hline 423.15 & $353.9 \pm 0.4$ & 239 & -115 \\
\hline 449.15 & $383.2 \pm 0.4$ & 240 & -143 \\
\hline 474.15 & $394.5 \pm 0.8$ & 233 & -162 \\
\hline
\end{tabular}

${ }^{a}$ The uncertainties of the calculated values are about \pm 3 per cent.

TABLE 4. Values of the parameters $a$ and $b$ of equation (3)

\begin{tabular}{lcc}
\hline Compound & $a /\left(\mathrm{J} \cdot \mathrm{K}^{-1} \cdot \mathrm{mol}^{-1}\right)$ & $b /\left(\mathrm{J} \cdot \mathrm{K}^{-2} \cdot \mathrm{mol}^{-1}\right)$ \\
\hline cis-1,2-Cyclohexanediol & $48 \pm 3$ & $-0.21 \pm 0.01$ \\
myo-Inositol & $270 \pm 7$ & $-0.92 \pm 0.02$ \\
\hline
\end{tabular}

By inserting equation (3) into (2), the following expression for the enthalpy of sublimation at the reference temperature $T_{\mathrm{o}}$ is obtained:

$$
\Delta_{\mathrm{sub}} H_{\mathrm{m}}^{\mathrm{o}}=\Delta_{\mathrm{sub}} H_{\mathrm{m}}(T)+a \cdot\left(T_{\mathrm{o}}-T\right)+(1 / 2) \cdot b \cdot\left(T_{\mathrm{o}}^{2}-T^{2}\right) .
$$

The values of the enthalpy of sublimation or vaporization of the solute substances and their respective standard values are presented in table 5. The sublimation enthalpy of myo-inositol was determined by Barone et al. ${ }^{(16)}$ and by de Wit et al. ${ }^{(20)}$ from the temperature coefficient 
TABLE 5. Enthalpy of sublimation $\Delta_{\mathrm{sub}} H_{\mathrm{m}}$ and vaporization $\Delta_{\mathrm{vap}} H_{\mathrm{m}}$ at temperatures $T$, and their standard values $\Delta_{\mathrm{sub}} H_{\mathrm{m}}^{\mathrm{o}}$ and $\Delta_{\mathrm{vap}} H_{\mathrm{m}}^{\mathrm{o}}$, respectively

\begin{tabular}{lccccc}
\hline Compound & $\frac{T}{\mathrm{~K}}$ & $\frac{\Delta_{\mathrm{sub}} H_{\mathrm{m}}}{\mathrm{kJ} \cdot \mathrm{mol}^{-1}}$ & $\frac{\Delta_{\mathrm{vap}} H_{\mathrm{m}}}{\mathrm{kJ} \cdot \mathrm{mol}^{-1}}$ & $\frac{\Delta_{\mathrm{sub}} H_{\mathrm{m}}^{\mathrm{o}}}{\mathrm{kJ} \cdot \mathrm{mol}^{-1}}$ & $\frac{\Delta_{\mathrm{vap}} H_{\mathrm{m}}^{\mathrm{o}}}{\mathrm{kJ} \cdot \mathrm{mol}^{-1}}$ \\
\hline Cyclohexanol & 300.15 & & $62.0 \pm 0.3$ & & $62.0 \pm 0.3$ \\
cis-1,2-Cyclohexanediol & 343.15 & $88 \pm 2$ & & $89 \pm 3$ & \\
myo-Inositol & 474.15 & $167 \pm 2$ & & $181 \pm 2$ & \\
\hline
\end{tabular}

of the vapour pressure. The value obtained in this work at $T=298.15 \mathrm{~K}$ is $3 \mathrm{~kJ} \cdot \mathrm{mol}^{-1}$ higher than that of Barone et al., ${ }^{(16)}$ and $2 \mathrm{~kJ} \cdot \mathrm{mol}^{-1}$ higher than that calculated at $T=298.15 \mathrm{~K}$ using the data of de Wit et al. The values found in the literature for cyclohexanol, at $T=298.15 \mathrm{~K}$, are $\Delta_{\text {vap }} H_{\mathrm{m}}=(62.01 \pm 0.29) \mathrm{kJ} \cdot \mathrm{mol}^{-1(21)}$ and $\Delta_{\mathrm{vap}} H_{\mathrm{m}}=(61.97 \pm 0.89)$ $\mathrm{kJ} \cdot \mathrm{mol}^{-1},{ }^{(22)}$ and are in close agreement with the results of the present work. We are not aware of any study on the sublimation of cis-1,2-cyclohexanediol.

The results given in table 2 were employed in the determination of the variation of $\Delta_{\mathrm{sol}} H_{\mathrm{m}}$ as a function of molality $m$ and the resulting equations are presented in table 6 .

By taking the limiting values $\Delta_{\text {sol }} H_{\mathrm{m}}^{\infty}$ (table 6) and those of the standard enthalpies of sublimation $\Delta_{\mathrm{sub}} H_{\mathrm{m}}^{\mathrm{o}}$ or vaporization $\Delta_{\mathrm{vap}} H_{\mathrm{m}}^{\mathrm{o}}$ (table 5), the standard enthalpies of solvation $\Delta_{\text {solv }} H_{\mathrm{m}}^{\infty}$ were calculated and the results are presented in table 7 . The uncertainties in the values of the enthalpies of solvation are similar to those surrounding the enthalpies of sublimation or vaporization of the solutes. The uncertainties are taken to be the standard errors.

\section{Discussion}

It has been shown that interaction between non-polar groups can lead to molecular association even in a dilute solution. Although aqueous solutions have been by far the most extensively studied systems, ${ }^{(23,24)}$ solute association has also been observed in other solvents. ${ }^{(25)}$ The hydroxyls can contribute to molecular association through hydrogen bonding. ${ }^{(26-28)}$ Thus, for the solutes studied here, molecular association can take place through polar or non-polar molecular interaction.

Inositol in DMSO is the only system for which no significant variation of $\Delta_{\mathrm{sol}} H_{\mathrm{m}}$ with molality is noted. For all the others, the enthalpy is molality dependent. Among all solvents, water gives rise to larger variations of $\Delta_{\mathrm{sol}} H_{\mathrm{m}}$ with molality.

For cyclohexanol, the less polar solute among those studied in this work, the slope of the $\Delta_{\mathrm{sol}} H_{\mathrm{m}}$ against $m$ curves is positive in water and negative in organic solvents. For myo-inositol, the more polar solute, a negative slope is observed in water and a positive one in other solvents. Cyclohexanediol shows some sort of intermediate behaviour between the two other solutes.

The heat of dilution of a large number of aqueous solutions of non-electrolytes has been measured and the pairwise enthalpy coefficients calculated. ${ }^{(29-31)}$ The signs of these coefficients are in agreement with those found for the slopes of $\Delta_{\text {sol }} H_{\mathrm{m}}$ against $m$ presented above. 
TABLE 6. Enthalpy of solution $\Delta_{\mathrm{sol}} H_{\mathrm{m}}$ as a function of molality $m$ at $T=298.15 \mathrm{~K}$

\begin{tabular}{ll}
\hline System & \multicolumn{1}{c}{ Equation } \\
\hline Cyclohexanol (W) & $\Delta_{\mathrm{sol}} H_{\mathrm{m}} /\left(\mathrm{kJ} \cdot \mathrm{mol}^{-1}\right)=-(8.72 \pm 0.02)+(2.43 \pm 0.06) \cdot\left(\mathrm{m} / \mathrm{m}_{\mathrm{o}}\right)^{a}$ \\
Cyclohexanol (FMD) & $\Delta_{\mathrm{sol}} H_{\mathrm{m}} /\left(\mathrm{kJ} \cdot \mathrm{mol}^{-1}\right)=(4.775 \pm 0.004)-(0.25 \pm 0.01) \cdot\left(\mathrm{m} / \mathrm{m}_{\mathrm{o}}\right)$ \\
Cyclohexanol (DMSO) & $\Delta_{\mathrm{sol}} H_{\mathrm{m}} /\left(\mathrm{kJ} \cdot \mathrm{mol}^{-1}\right)=(6.064 \pm 0.005)-(0.32 \pm 0.02) \cdot\left(\mathrm{m} / \mathrm{m}_{\mathrm{o}}\right)$ \\
cis-1,2-Cyclohexanediol (W) & $\Delta_{\mathrm{sol}} H_{\mathrm{m}} /\left(\mathrm{kJ} \cdot \mathrm{mol}^{-1}\right)=(6.410 \pm 0.008)+(1.70 \pm 0.03) \cdot\left(\mathrm{m} / \mathrm{m}_{\mathrm{o}}\right)$ \\
cis-1,2-Cyclohexanediol (FMD) & $\Delta_{\mathrm{sol}} H_{\mathrm{m}} /\left(\mathrm{kJ} \cdot \mathrm{mol}^{-1}\right)=(18.51 \pm 0.02)+(0.34 \pm 0.07) \cdot\left(\mathrm{m} / \mathrm{m}_{\mathrm{o}}\right)$ \\
cis-1,2-Cyclohexanediol (DMSO) & $\Delta_{\mathrm{sol}} H_{\mathrm{m}} /\left(\mathrm{kJ} \cdot \mathrm{mol}^{-1}\right)=(19.10 \pm 0.04)+(0.4 \pm 0.2) \cdot\left(\mathrm{m} / \mathrm{m}_{\mathrm{o}}\right)$ \\
myo-Inositol (W) & $\Delta_{\mathrm{sol}} H_{\mathrm{m}} /\left(\mathrm{kJ} \cdot \mathrm{mol}^{-1}\right)=(15.57 \pm 0.01)-(1.10 \pm 0.04) \cdot\left(\mathrm{m} / m_{\mathrm{o}}\right)$ \\
myo-Inositol (FMD) & $\Delta_{\mathrm{sol}} H_{\mathrm{m}} /\left(\mathrm{kJ} \cdot \mathrm{mol}^{-1}\right)=(14.753 \pm 0.004)+(0.39 \pm 0.05) \cdot\left(\mathrm{m} / m_{\mathrm{o}}\right)$ \\
myo-Inositol (DMSO) & $\Delta_{\mathrm{sol}} H_{\mathrm{m}} /\left(\mathrm{kJ} \cdot \mathrm{mol}^{-1}\right)=(11.70 \pm 0.01)$ \\
\hline \hline
\end{tabular}

$a_{m_{\mathrm{o}}}=1.0 \mathrm{~mol} \cdot \mathrm{kg}^{-1}$.

TABLE 7. Standard enthalpy of solvation $\Delta_{\text {solv }} H_{\mathrm{m}}^{\infty}$ for hydroxyl cyclohexane derivatives in different solvents at $T=298.15 \mathrm{~K}$

\begin{tabular}{lccc}
\hline & \multicolumn{3}{c}{$\Delta_{\text {solv }} H_{\mathrm{m}}^{\infty} /\left(\mathrm{kJ} \cdot \mathrm{mol}^{-1}\right)$} \\
Solute: & Cyclohexanol & cis-1,2-Cyclohexanediol & myo-Inositol \\
Solvent & & & \\
\hline W & -70.7 & -82.4 & -165.8 \\
FMD & -57.2 & -70.3 & -166.6 \\
DMSO & -55.9 & -69.7 & -169.7 \\
\hline
\end{tabular}

TABLE 8. Group contribution to the enthalpy of solvation $\Delta_{\text {solv }} H_{\mathrm{m}}^{\infty}$ of hydroxyl cyclohexane derivatives in different solvents at $T=298.15 \mathrm{~K}$

\begin{tabular}{lll}
\hline & \multicolumn{2}{c}{$\Delta_{\text {solv }} H_{\mathrm{m}}^{\infty} /\left(\mathrm{kJ} \cdot \mathrm{mol}^{-1}\right)$} \\
\cline { 2 - 3 } Solvent & $\mathrm{CH}_{2}$ & $\mathrm{CHOH}$ \\
\hline $\mathrm{W}$ & -8.0 & -27.5 \\
FMD & -5.1 & -27.6 \\
DMSO & -4.7 & -28.1 \\
\hline
\end{tabular}

The results obtained for $\Delta_{\text {solv }} H_{\mathrm{m}}^{\infty}$ show that in any solvent, the solute $\mathrm{OH}$ group gives an important contribution to the enthalpy of solvation. In fact, as the number of $\mathrm{OH}$ groups increases, a considerable decrease in $\Delta_{\text {solv }} H_{\mathrm{m}}^{\infty}$ is observed. Although the variation of $\Delta_{\text {solv }} H_{\mathrm{m}}^{\infty}$ per $\mathrm{CH}_{2}$ is smaller than that observed for $\mathrm{OH}$, it is nevertheless significant. Despite the limited scope of the results presented here it is useful to estimate, from the data presented in table 7, the contribution of $\mathrm{CH}_{2}$ and $\mathrm{CHOH}$ to the enthalpy of solvation. The results obtained are given in table 8 .

The values of the enthalpy of solvation of cyclohexanol and cyclohexanediol in water are more negative than those observed in the other solvents. For myo-inositol, no significant 
difference is observed for $\Delta_{\text {solv }} H_{\mathrm{m}}^{\infty}$ in all solvents. It is well established that solvation of non-polar solutes in water occurs with negative entropy and enthalpy, and positive heat capacity and Gibbs energy. These results have been interpreted on the basis of molecular terms as arising from an increase in the structural organization of the water around the solute non-polar groups. ${ }^{(32)}$ However, the interpretation of results observed for the thermodynamic properties of non-polar compounds in water still remains an open question. ${ }^{(33)}$

The results obtained for the enthalpy of solvation show that this thermodynamic property can be used to derive information on both the polar and the non-polar parts of the solutes. It is therefore a useful property for studying solvation. However, its molecular interpretation is not an easy matter and will be the subject of a forthcoming paper.

\section{REFERENCES}

1. Hamilton, D.; Stokes, R. H. J. Solution Chem. 1972, 1, 213-221.

2. Dack, M. R. J. Aust. J. Chem. 1975, 28, 1643-1648.

3. Riddick, J. A.; Bunger, W. B. Organic solvents, physical properties and methods of purification. In Techniques of Chemistry, Vol. 2. Weissberger, A.: editor. Wiley-Interscience: New York. 1970.

4. Lankford, J. I.; Criss, C. M. J. Solution Chem. 1987, 16, 753-765.

5. Barta, L.; Kooner, Z. S.; Hepler, L. G.; Roux-Desgranges, G.; Grolier, J.-P. E. J. Solution Chem. 1989, 18, 663-673.

6. Aznarez, S. B.; Mussari, L.; Postigo, M. A. J. Chem. Eng. Data 1993, 38, 270-273.

7. Perrin, D. D.; Armarego, W. L. F. Purification of Laboratory Chemicals: 3rd edition. Pergamon Press: Oxford. 1988.

8. de Wit, H. G. M.; de Kruif, C. G.; van Miltenburg, J. C. J. Chem. Thermodynamics 1983, 15, 891-902.

9. Martin, D.; Weise, A.; Niclas, H.-J. Angew. Chem., Int. Ed. Engl. 1967, 6, 318-334.

10. Thomas, R.; Shoemaker, C. B.; Eriks, K. Acta Crystallogr. 1966, 21, 12-20.

11. Clever, H. L.; Westrum, Jr., E. F. J. Phys. Chem. 1970, 74, 1309-1317.

12. Kelley, K. K. J. Am. Chem. Soc. 1929, 51, 1400-1406.

13. Adachi, K.; Suga, H.; Seki, S. Bull. Chem. Soc. Jpn 1968, 41, 1073-1087.

14. Mayer, J.; Rachwalska, M.; Sciesinska, E.; Sciesinski, J. J. Phys. France 1990, 51, 857-867.

15. Maria, T. M. R.; Costa, F. S.; Leitão, M. L. P.; Redinha, J. S. Thermochim. Acta, 1995, 269/270, 405-413.

16. Barone, G.; Della Gatta, G.; Ferro, D.; Piacente, V. J. Chem. Soc. Faraday Trans. 1990, 86, 75-79.

17. Kilday, M. V. J. Res. Natl. Bur. Stand. 1980, 85, 467-481.

18. Reid, R. C.; Prausnitz, J. M.; Sherwood, T. K. The Properties of Gases and Liquids: 3rd edition. McGraw-Hill: New York. 1977.

19. Rihani, D. N.; Doraiswamy, L. K. Ind. Eng. Chem. Fundam. 1965, 4, 17-21.

20. de Wit, H. G. M.; Bouwstra, J. A.; Blok, J. G.; de Kruif, C. G. J. Chem. Phys. 1983, 78, $1470-1475$.

21. Wadsö, I. Acta Chem. Scand. 1966, 20, 544-552.

22. Cabani, S.; Conti, G.; Mollica, V.; Lepori, L. J. Chem. Soc. Faraday Trans. I 1975, 71, 1943-1952.

23. Kauzmann, W. Adv. Protein Chem. 1959, 14, 1-63.

24. Tanfold, P. The Hydrophobic Effect. Plenum Press: London. 1980.

25. Yaacobi, M.; Ben-Naim, A. J. Phys. Chem. 1974, 78, 175-178.

26. Etter, M. C. Acc. Chem. Res. 1990, 23, 120-126.

27. Rebek, J. Angew. Chem., Int. Ed. Engl. 1990, 29, 245-255.

28. Dado, G. P.; Desper, J. M.; Gellman, S. H. J. Am. Chem. Soc. 1990, 112, 8630-8632.

29. Savage, J. J.; Wood, R. H. J. Solution Chem. 1976, 5, 733-750.

30. Barone, G.; Bove, B.; Castronuovo, G.; Elia, V. J. Solution Chem. 1981, 10, 803-809. 
31. Andini, S.; Cacace, P.; Castronuovo, G.; Elia, V.; Racioppoli, F. J. Chem. Soc. Faraday Trans. 1993, 89, 503-507.

32. Frank, H. S.; Evans, M. W. J. Chem. Phys. 1945, 13, 507-532.

33. Pratt, L. R. Ann. Rev. Phys. Chem. 1985, 39, 433-449.

(Received 8 June 1998; in final form 22 January 1999)

WA98/029 